\title{
How Social Network Characteristics Affect Users' Trust and Purchase Intention
}

\author{
Min-Chung $\operatorname{Han}^{1}$ \\ ${ }^{1}$ New York Institute of Technology (NYIT), School of Management, Nanjing, China \\ Correspondence: (Amanda) Min-Chung Han, Assistant Professor, New York Institute of Technology, School of \\ Management, Nanjing, China. E-mail: mhan07@nyit.edu
}

Received: March 7, 2014

Accepted: June 4, 2014

Online Published: July 25, 2014

doi:10.5539/ijbm.v9n8p122

URL: http://dx.doi.org/10.5539/ijbm.v9n8p122

\begin{abstract}
These days, young college students cannot imagine life without social network service (SNS). They access and browse social network sites everyday to get information, find friends, enjoy entertainment, and express their opinion. Despite an extraordinary amount of time consumed on SNS by young adults, there have not been extensive researches and discussion of social networking services and their impact on purchase intention. The aim of this research is to discover how SNS characteristics affect SNS users' trust and purchase intention in Chinese SNS Weibo. Regression analysis from the SPSS 13.0 program was used to conduct the research. This research identified the social network characteristic (informativeness) that affects trust in Weibo. This article also suggests variables (trust and informativeness) that have an effect on the purchase intention on the Weibo. Thus, we hope this study will help practitioners and companies that can formulate appropriate marketing strategies on social network platforms when selling their products and service.
\end{abstract}

Keywords: social network service, trust, purchase intention, Weibo, social commerce

\section{Introduction}

Social networking service also known as Social media has been the most popular marketing tool and at the same time the most promising Internet service in the industry because more and more people join social networks to get information, find friends, seek entertainment, and express their opinion.

The most popular Social Networking Service (SNS) worldwide is Facebook in the United States. It has strong competitors such as Kakao Story (South Korea), Renren (China), and Weibo (China) in Asia. As SNS has gained popularity especially among young adults, it became the center of Internet marketing strategies.

According to CNET, Facebook has 1.06 billion monthly active users, 618 million daily active users and 680 million monthly mobile active users as of December 2012. Telegraph reported that Twitter has 500 million accounts, with 200 million accounts being regular users. In a day, around 500 million tweets are exchanged in the site as of December 2012.

However, the number of users in Facebook and Twitter is not big enough in Asia particularly in China. Facebook, Twitter and Youtube do not have official presence in the Chinese market because the Chinese government bans Western Social Networking Services. Language barrier is another factor that discourages Chinese Internet users from using American SNS. Therefore, multinational corporations in China are focusing on local Chinese SNS to promote its services and products.

The Twitter equivalent Weibo surpassed its biggest competitor, Chinese Facebook Renren, in terms of user number. Weibo is a common term for microblog in China. The Chinese microblog Weibo is a combination of Facebook and Twitter. Within 140 words, people exchange their opinions and ideas with photos.

As the popularity of SNS has become high, the spending on SNS advertisement has increased. According to China Internet Watch, The social network advertisement spent in China is estimated to reach $\$ 612.8$ million by the end of 2013.

Social network service companies also have become a platform for Web marketing. Recently, SNS try to turn to a sales platform. E-commerce giant Alibaba group invested a huge amount of money ( $\$ 586$ million) in the microblog Sina Weibo in April, 2013. Industry experts suggested that Alibaba might be interested in selling Taobao (The biggest e-commerce site in China owned by the Alibaba group) products on Weibo. Anyone who 
uses Internet in China knows Taobao but they would visit Taobao site when they need to buy something only while 50 million people would visit Weibo site whenever to discuss news, to simply talk to friends, and to pass time. Selling products on Weibo has been already tested by selling Xiaomi phone. The smart phone maker Xiaomi offered to sell 50,000 MI2 phones to Weibo users in Dec. 2012. According to TechinAsia site the result was an astonishing 1.3 million reservations in just over 5 minutes.

Since social commerce is a recent phenomenon, there have not been extensive researches discussing social commerce on social networking platform and its impact on purchase intention. Many of previous social commerce studies were limited to social commerce sites which are merely group purchasing sites. Issues related to connecting social networks and online commerce activities on social networks have not been extensively studied. This research aims to find out how SNS characteristics affect the trust and purchase intention of users. This study, therefore, contributes to corporations learning what aspects of SNS actually make users buy and trust products and services.

The study is organized as follow: First, the study reviews relevant literature on social commerce and social network. Second, the study explains the research questions and methodology. Third, the study discusses the findings of analysis. Finally, the study concludes with a general discussion of the results and makes suggestions for further study.

\section{Literature Review}

\subsection{Social Commerce Definition}

Social commerce is, generally put, a commerce activity where users interact with a Social Networking Service (SNS). The term "social commerce" was first used in 2005 by the Yahool! Sphoposphere \& Pick Lists website.

Some researchers distinguished the difference between social commerce and social shopping. Stephen and Toubia (2010) concluded that social shopping connects customers while social commerce connects sellers. They stated that social commerce as "an emerging trend in which sellers are connected in online social networks and sellers are individuals instead of firms." In the research, social commerce sellers are individuals, not corporations nor firms. Therefore, selling Xiaomi phones on Weibo is not considered social commerce by their definition.

Rad and Benyoucef (2011) disagreed with the idea claiming that social commerce refers to both the networks of sellers and networks of buyers because social commerce should encapsulate both customers and sellers.

Gurty and Zhang (2011) described social commerce as commerce activities mediated by social media. Many social commerce sites are actually more of offsite social commerce sites. Online commerce sites use SNS to attract customers or to let them share their opinion about the product or service on the separated SNS sites.

Group purchasing websites such as Groupon are considered as the most well-known social commerce site; however, it is not adequate to limit social commerce to group purchasing. In this study, social commerce refers to onsite social commerce which means online commerce that is conducted on a social network website without leaving the site itself. Although onsite social commerce is in a very early emerging state, social commerce on Facebook and Twitter already appeal to people under the name of F-commerce and $\mathrm{T}$ (witter)-commerce.

\subsection{The nature of Social Network Service}

Previous researches about online communities were reviewed to examine the significant factors that affect trust in social network. A literature review was conducted and extensively focused on the nature of online community which could apply to social networks. Four factors, namely interactivity, informativeness, convenience of use, and brand reputation, were chosen as characteristics of the social network through previous researches.

\subsubsection{Interactivity}

Interactivity is one of the most significant social network service characteristics. Instead of receiving information unilaterally, a social network service allows users to communicate mutually. Users are mostly content consumers on social network but if they want, they can also be content providers. Tweeting and/or reposting on others' posts are most common activities happening in social media.

There are several definitions of "interactivity". The Collins English dictionary defines interactivity as "the possibility for direct communication between the user and the computer, or the viewer and the television. Jones and Rafaeli (1999) defined that interactivity is "not a characteristic of the medium but the extent to which messages in a sequence relate to each other". Rafaeli and Sudweeks (1997) claimed, "Like face-to-face communication, computer-mediated communication has the capacity of enabling high interactivity while interactivity can lead to sociability".

Numerous previous researches have supported the hypotheses that interactivity enhances loyalty, repurchase intention, 
and brand preference. Lee (2012) argued that interaction leads to the formation of relationship, which leads to the deepening of the relationship (identification) and finally to brand loyalty. Interactivity and trust affect each other in the case of online travel community (Wu \&Chang, 2005).

Interactivity is also related to web site quality. Online interactivity dimensions: playfulness, connectedness, and reciprocal communication were proven to be important predictors of web site quality (Chen \& Yen, 2004).

Some argue that there is a problem when interactivity and interaction can be used interchangeably. Interaction refers to reciprocal action while interactivity refers to the quality or condition of interaction (Sedig et al., 2012). In this research, we use the term "interactivity" which includes the quality of interaction and reciprocal action.

\subsubsection{Informativeness}

Informativeness is literally defined as "an informative quality" in the Collins dictionary.

One of the biggest motivations to join SNS is the information seeking motivation (Borgatti \& Cross, 2003). Online community represents an important source to get information for consumers and community members easily turn to each other for information (Muniz \& O'Guinn, 2001).

Reliable information and good information quality are vital for users to make their decision because the users cannot physically examine the products that they want to purchase (Li et al., 2012). Therefore, SNS users need adequate information to make their purchase decision. That is why informativeness often leads to a positive SNS satisfaction, and to consumer's satisfaction in Internet shopping (Kim \& Lim, 2011).

Informativeness as one of the service quality variables of social commerce has a similar result. It has a positive influence upon the satisfaction of social commerce. However, informativeness does not have a significant influence upon repurchase intention (Jin \& Lee, 2012).

Informativeness also has a positive effect on consumers' returning to the webiste. Informativeness and interactivity of website positively affect the attitude toward the website. It also leads to a strong influence on the return-visit intention to the website (An \& Kim, 2008)

\subsubsection{Convenience of Use}

Convenience of use or ease of use generally pertains to ease of use and information search (Yoo \& Donthu, 2000). Convenience of use is one of the important reason to choose online shopping mall as well as information quality (Kim \& Lim, 2011)

There were researches suggesting that perceived ease of use may actually be a causal antecedent to perceived usefulness (Gefen \& Straub, 2000). Perceived ease of use was also significantly correlated with current usage and future usage (Davis, 1989). Convenience of use was proven as one of the most important quality criteria of an Internet shopping site that influence consumer attitudes and behaviors (Yoo \& Donthu, 2000).

\subsection{Trust and Purchase Intention on Social Network}

Many factors that affect trust in an online environment were studied in previous researches. One of them was perceived reputation. The perceived reputation on power blogs had a positive effect in the trust in power blogs. The perceived trust in power blogs could lead to a positive attitude toward products and/or service which are introduced in the power blog (Yun et al., 2012).

There are many factors proven to affect purchase intention on web sites, including trust in the web site. Loyalty in an online shopping mall community affects repurchase intention in a positive way (Lee, 2011).

Online trust can be built through the belief that the online shopping mall would not get any favorable returns by cheating or by ease of use. Also the trust in the online shopping mall produces online purchase intention (Gafen et al., 2003).

In addition, an attitude toward products and/or services featured in power blogs has been found that positively affects purchase intention (Yun et al., 2012). Interactivity also positively affects the purchase intention, while privacy risk and shipping risk negatively affect purchase intention (Lee et al., 2011).

\section{Research Methodology and Questions}

\subsection{Research Questions and Framework}

Social commerce is a relatively recent phenomenon and has been limited to group purchasing activities. There were researches discussing how to use famous Social Networking Services to lead users of an online marketplace to boost sales. However, very little is understood about whether social network characteristics could lead the users to buy products or service on the Social Networking Service's platform itself. Therefore, this research examines the following questions in relation to social commerce: 
RQ 1. Do social network characteristics influence social network users' trust?

1-1. Does interactivity influence social network users' trust?

1-2. Does informativeness influence social network users' trust?

1-3. Does convenience of use influence social network users' trust?

RQ 2. Does social network trust influence the purchase intention of social commerce users?

RQ 3. Do social network characteristics influence the purchase intention of social commerce users?

3-1. Does interactivity influence the purchase intention of social network users?

3-2. Does informativeness influences the purchase intention of social commerce users?

3-3. Does convenience of use influence the purchase intention of social commerce users?

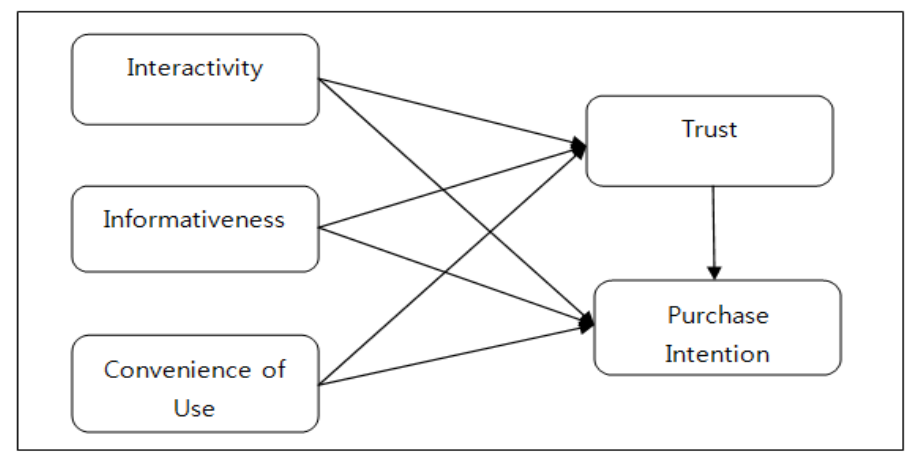

Figure 1. Research model

\subsection{Research Methodology}

Using convenience sampling, this research targeted young regular SNS users in China. The survey was conducted through e-mail. The respondents are all Chinese university students in their early 20's living in Nanjing, China. The results were analyzed using t-test and regression analysis from the SPSS 13.0 computer software program.

The research variables in this study were modified accordingly based on the previous researches' reliability and validity verified variables in case of need. All the items were measured by Likert 5 scale. The list of measurement items are shown in Table 1 below.

Using the Ducoffe model as a base, a self-administered survey instrument rooted in the questionnaire developed by Ducoffe (1996) was constructed.

This survey instrument was composed of four major sections. Within the first section, subjects were asked to respond to two demographic questions: gender and age. The second section of this research contained questions designed to understand their Weibo usage patterns. In the third section of the research, students were asked to indicate their online shopping patterns. The last section of this research contained questions designed to elicit their response toward Weibo and Social Network Service in general on a 5 point scale. 
Table 1. Operational definition of variables

\begin{tabular}{|c|c|c|}
\hline Variables & Operational Definition & Authors \\
\hline Interactivity & $\begin{array}{l}\text { When I access Weibo, the response is fast } \\
\text { Pages on Weibo I visit, usually load quickly } \\
\text { I often post my writings or photos on Weibo }\end{array}$ & Novak, Hoffman\& Yung (1999) \\
\hline Informativeness & $\begin{array}{l}\text { Weibo is a good source of product information } \\
\text { Weibo supplies relevant product information } \\
\text { Weibo provides timely information } \\
\text { Weibo provides up-to-date product information } \\
\text { Weibo is a convenient source of product information }\end{array}$ & Ducoffe (1996) \\
\hline Convenience & $\begin{array}{l}\text { Weibo is easy to learn how to use } \\
\text { Weibo is flexible to interact with } \\
\text { Weibo is easy to become skillful at using } \\
\text { Weibo is easy to use } \\
\text { Weibo is easy to search for information }\end{array}$ & $\begin{array}{c}\text { Davis (1989) } \\
\text { Yoo \& Donthu (2000) }\end{array}$ \\
\hline Trust & $\begin{array}{l}\text { Weibo is credible } \\
\text { Weibo is trustworthy } \\
\text { Weibo is believable } \\
\text { Weibo cares of customers } \\
\text { Weibo is honest }\end{array}$ & $\begin{array}{c}\text { Brackett\&Carr (2001) } \\
\text { Gefen et al. (2003) }\end{array}$ \\
\hline Purchase Intention & $\begin{array}{l}\text { I will definitely buy the product from Weibo } \\
\text { It is likely that I will purchase the product from Weibo in the near future } \\
\text { I intend to learn how to buy from Weibo } \\
\text { I think Weibo is a good place to buy products }\end{array}$ & Yoo \& Donthu (2000) \\
\hline
\end{tabular}

\section{Research Findings}

\subsection{Sample Demographics}

The sample in this research consisted of college students in the area of south China, Jiangsu province. Data for this study were collected in August 2013 from Chinese university students who had a Sina Weibo account. A total of 220 students completed the survey. Among those who completed the survey, 212 samples were considered as valid samples after removing 8 respondents who did not answer all the questions.

More than half of the respondents were female students (62.7\%). It is not surprising to have such gender proportion considering young Weibo users' gender proportion (among the 19-22 age Weibo users group, more than half $(53.9 \%)$ of the users were female users). Respondents were all university students: therefore, most of them were in their early 20's with only 2 people over 25 .

When they were asked how often they used Weibo, half of them (48.6\%) answered that they used it every day. The amount of time they spent on Weibo was quite a lot. Half of them $(51.9 \%)$ answered they used Weibo service about 10 minutes to half an hour each time. A quarter of the respondents $(24.5 \%)$ answered that they used Weibo more than half an hour. Half of the respondents (48.6\%) started using Weibo between 1 year and 3 years ago. Only $17.4 \%$ answered that they started using Weibo less than 6 months ago.

More than half of respondents (51.6\%) were not actively using Weibo answering they don't really or never post a review on the site. Only $9 \%$ of the respondents answered they often or always leave reviews of the service and products that they purchased or experienced. A quarter of respondents $(24.5 \%)$ were avid online shoppers buying more than once a week through online shopping. More than half $(54.8 \%)$ purchased products online once or twice a month. A majority of respondents (72.7\%) answered they spent less than $300 \mathrm{RMB}$ each time when they shop. Considering they are all university students, the amount of money they spent on shopping was not high. 
Table 2. Sample characteristics

\begin{tabular}{|c|c|c|c|}
\hline Types & & Number & Ratio (\%) \\
\hline \multirow{2}{*}{ Gender } & Male & 79 & 37.3 \\
\hline & Female & 133 & 62.7 \\
\hline \multirow{5}{*}{ How often do you use Weibo? } & Everyday & 103 & 48.6 \\
\hline & $2 \sim 3$ times a week & 61 & 28.8 \\
\hline & Once a week & 18 & 8.5 \\
\hline & $2 \sim 3$ times a month & 20 & 9.4 \\
\hline & Less than once a month & 10 & 4.7 \\
\hline \multirow{5}{*}{ How long do you spend time on the weibo site each visit? } & Less than $10 \mathrm{~min}$ & 50 & 23.6 \\
\hline & $10 \sim 30 \mathrm{~min}$ & 110 & 51.9 \\
\hline & 30 min $\sim 1$ hour & 38 & 17.9 \\
\hline & $1 \sim 2$ hour & 10 & 4.7 \\
\hline & More than 2 hour & 4 & 1.9 \\
\hline \multirow{5}{*}{ When did you start using Weibo? } & Less than a month ago & 3 & 1.4 \\
\hline & 1 month $\sim 6$ month ago & 34 & 16.0 \\
\hline & 6 month $\sim 1$ year ago & 53 & 25.0 \\
\hline & 1 year 3 year ago & 103 & 48.6 \\
\hline & more than 3 years ago & 19 & 9.0 \\
\hline \multirow{5}{*}{ Do you leave reviews of products and service on Weibo? } & Never & 33 & 15.6 \\
\hline & Not really & 77 & 36.3 \\
\hline & Sometimes & 83 & 39.2 \\
\hline & Often & 12 & 5.7 \\
\hline & Always & 7 & 3.3 \\
\hline \multirow{5}{*}{ How often do you shop online? } & More than once a week & 27 & 12.7 \\
\hline & Once a week & 25 & 11.8 \\
\hline & Once in two weeks & 58 & 27.4 \\
\hline & Once in a month & 58 & 27.4 \\
\hline & Less than once a month & 44 & 20.8 \\
\hline \multirow{7}{*}{ What is the average purchasing amount each time? } & Less than 100RMB & 58 & 27.4 \\
\hline & 100 300RMB & 96 & 45.3 \\
\hline & 300 500RMB & 42 & 19.8 \\
\hline & $500 \sim 1000 \mathrm{RMB}$ & 14 & 6.6 \\
\hline & 1000 2000RMB & 1 & 0.5 \\
\hline & 2000 3000RMB & 1 & 0.5 \\
\hline & More than 3000RMB & 0 & 0 \\
\hline
\end{tabular}

\subsection{Validity and Reliability}

A list of 13 social network service characteristic sub-factors was generated based on literature review. For a confirmatory factor analysis for the validation of the research variables SPSS 13.0 program was used. The sub-factors of social network characteristics were grouped into 3 variables such as interactivity, informativeness, and convenience of use. Each variable was assessed for validity by conducting a principal components analysis with varimax rotation. It is proposed that each sub-factor should have a minimum communality of 0.4 for acceptable validity.

A total of 4 sub-factors of characteristics (Interactivity 3; Informativeness 4, 5; Convenience 5) were removed 
from the scale because they were not consistent with the rest. Convenience 5 was removed from sub-factors due to its low communality. Total 9 sub-factors were collected as characteristics of social network site Weibo.

Cronbach's alpha was used to check variable reliabilities. Generally if Cronbach's alpha coefficient exceeds 0.70 , then it is considered as the standard acceptance norm. In this research, three social network characteristics variables' Cronbach's alpha coefficient exceeded 0.70; however, the Cronbach's coefficient of interactivity was less than 0.70 . Thus, the interactivity variable was removed from the independent variables. Among convenience sub-factors the Cronbach's coefficient (.847) would be higher (.863) if convenience 2 is deleted. Therefore, the sub-factor convenience 2 is deleted for a reliable research.

Table 3. Validity and reliability

\begin{tabular}{|c|c|c|c|c|c|c|}
\hline \multirow{2}{*}{ Variables } & \multicolumn{5}{|c|}{ Factor Loadings } & \multirow{2}{*}{ Cronbach's Alpha } \\
\hline & 1 & 2 & 3 & 4 & Communality & \\
\hline Conve4 & .853 & & & & .782 & \multirow{4}{*}{.847} \\
\hline Conve3 & .791 & & & & .790 & \\
\hline Conve2 & .743 & & & & .518 & \\
\hline Conve1 & .513 & & & & .769 & \\
\hline Inform2 & & .821 & & & .718 & \multirow{3}{*}{.751} \\
\hline Inform1 & & .784 & & & .724 & \\
\hline Inform3 & & .642 & & & .544 & \\
\hline Intera2 & & & & .879 & .786 & \multirow{2}{*}{.655} \\
\hline Intera1 & & & & .797 & .718 & \\
\hline Eigen Value & 2.488 & 2.260 & 1.604 & 1.582 & & \\
\hline Variance $\%$ & 22.621 & 20.550 & 14.581 & 14.378 & & \\
\hline
\end{tabular}

\subsection{Trust and Purchase Intention}

A correlation analysis was performed before conducting a regression analysis to see the correlations between convenience and informativeness variables. Convenience variable had a positive Pearson Correlation Coefficient (.609) to informativeness. The coefficient value is high. That means that if convenience characteristic increases, then informativeness characteristic also increases. These two variables have a high correlation.

Table 4. Correlation analysis

\begin{tabular}{ccccc}
\hline \multirow{2}{*}{ Scale } & Mean & \multirow{2}{*}{ Std. } & \multicolumn{2}{c}{ Correlations } \\
\cline { 4 - 5 } & & Deviation & 1 & 2 \\
\hline Convenience & 4.112 & .780 & 1.00 & .609 \\
\hline Informativeness & 3.929 & .718 & .609 & 1.00 \\
\hline
\end{tabular}

RQ 1. Do social network characteristics influence social network users' trust?

Table 5. Trust in Weibo

Note. $\mathrm{p}<.05 *$.

\begin{tabular}{cccc}
\hline \multirow{2}{*}{ Variables } & \multicolumn{3}{c}{ Trust } \\
\cline { 2 - 4 } & $\beta$ & $\mathrm{t}$ & P-value \\
\hline Convenience & .053 & .638 & .518 \\
\hline Informativeness & .328 & 4.035 & $.000^{*}$ \\
\hline
\end{tabular}

To see if the social network characteristics affect social network users' trust, regression analysis was performed. For the analysis, two variables were taken as independent variables with trust as a dependant variable. It is considered as the 
standard acceptance norm when $\mathrm{t}$-value is higher than \pm 1.96 . A standard acceptance norm of P-value is less than 0.05 .

In the first research question, we tried to find if there was a relation between independent variables and dependent variables. As it is shown below, there is a significant relation between informativeness and trust. The t-value (4.035) between informativeness and trust is higher than \pm 1.96 with P-value $(0.000)$ less than 0.05 . Therefore, informativeness positively affect trust in Weibo. However, convenience does not have a significant effect on trust with t-value less than \pm 1.96 and P-value bigger than 0.05 . To sum up, if people find Weibo informative, they also find Weibo reliable and trustworthy.

RQ 2. Does social network trust influence the purchase intention of the social commerce users?

Table 6. Trust and purchase intention

\begin{tabular}{|c|c|c|c|c|c|c|}
\hline \multirow{2}{*}{ Variables } & \multicolumn{3}{|c|}{ Purchase Intention 1} & \multicolumn{3}{|c|}{ Purchase Intention 2} \\
\hline & $\beta$ & $\mathrm{t}$ & P-value & $\beta$ & $\mathrm{t}$ & P-value \\
\hline Trust & .388 & 6.093 & $.000^{*}$ & .351 & 5.431 & $.000^{*}$ \\
\hline
\end{tabular}

Note. $\mathrm{p}<.05 *$.

In the second question, we tried to find if there was a relation between trust and purchase intention. To see if trust affects purchase intention differently depending on products, we took high-involvement product (purchase intention 2) and low-involvement product (purchase intention 1) to ask the respondents' purchase intention. We asked the respondents if they want to buy a laptop computer (high-involvement) or T-shirt (low-involvement) in a fictional situation where Weibo sells products online. It turned out that trust had a positive effect on purchase intention regardless of the level of product involvement.

RQ 3. Do social network characteristics influence the purchase intention of the social commerce users?

Table 7. SNS characteristics and purchase intention

\begin{tabular}{ccccccc}
\hline \multirow{2}{*}{ Variables } & \multicolumn{3}{c}{ Purchase Intention 1 } & \multicolumn{3}{c}{ Purchase Intention 2 } \\
\cline { 2 - 7 } & $\beta$ & $\mathrm{t}$ & $\mathrm{P}$-value & $\beta$ & $\mathrm{t}$ & P-value \\
\hline Convenience & -.074 & -.850 & .396 & -.183 & -2.138 & $0.034^{*}$ \\
\hline Informativeness & .149 & 1.716 & .088 & .227 & 2.647 & $0.009^{*}$ \\
\hline
\end{tabular}

Note. $\mathrm{p}<.05 *$.

In the third question, we tried to find if the social network characteristics affect purchase intention. Convenience of use showed a negative effect on purchase intention 2 with $t$-value (-2.138) higher than \pm 1.96 and P-value (0.034) less than 0.05 . This means that convenience of use of social network service does not affect a purchase intention when a person wants to buy a high-involvement product (in this research, a laptop computer). This can be interpreted that people spend more time and effort to buy a high-involvement product; therefore, convenience of use does not have positive relation to purchase intention.

Informativeness had a positive effect on purchase intention 2 with t-value (2.647) higher than \pm 1.96 and P-value (0.000) less than 0.05 . However, informativeness did not have a significant impact on purchase intention 1 . When people want to buy a high-involvement product, they tend to collect information and spend time to consider options. Therefore, informativeness on Weibo helps people buy a high-involvement product on Weibo. Meanwhile, low-involvement product, people do not need much information to make a decision therefore, informativeness on Weibo did not have much impact on purchase intention. It can be interpreted that people come to Weibo to seek detailed information and reviews of a product or service that might help them to make a purchase decision.

\section{Discussion}

Despite the rapid growth of social network service, there has not been extensive research and discussion of social network service and their impact on purchase intention. Many of the previous social commerce studies were limited to group purchasing sites and issues related to connecting social networks. Additionally, online commerce activities on social networks have not been well discussed/researched.

The aim of this research was to find out how SNS characteristics affect the trust and purchase intention of SNS users. 
The contribution of this study to academic research, companies and practitioners was in learning what aspects of SNS actually make users buy and trust products and services.

The findings of this research show that $48.6 \%$ of Chinese university students surveyed visit the SNS, Weibo, once a day and $76.4 \%$ of them spend more than 10 minutes each time/visit. About a quarter of the respondents $(24.5 \%)$ answered that they used Weibo more than half an hour 30 minutes each time. About half of the respondents (48.6\%) started using Weibo between 1 year and 3 years ago. Only 17.4\% of respondents answered that they started using Weibo less than 6 months ago.

Result for the first research question- which social network characteristics influence social network users' trust- showed that informativeness had a positive effect on trust, but convenience of use did not have a significant impact on trust. Many respondents find social network service convenient to use, but this does not seem to affect trust of SNS, unlike informativeness. Thus it can be inferred that a social network service site which offers extensive amount of information of products or services could gain the trust of users, more than a site which does not offer such information. If a corporation wants to earn trust from SNS users, it should provide adequate information about products or services on SNS.

Correlations for the second research question- does social network trust affect purchase intention on SNS- showed that trust of SNS has a positive effect on purchase intention of both high-involvement and low-involvement products on SNS. Therefore, it can be surmised that trust of social network influences the purchase intention of social commerce users. To attract customers to social commerce of Weibo, it would be important to build their trust in Weibo.

As for the third research question- whether social network characteristics influence purchase intention of SNS usersshowed that both social network characteristics (informativeness and convenience of use) did not have a significant effect on purchase intention 1 (low-involvement product). It could therefore be interpreted that people do not want to search much information when buying low-involvement products which are mostly cheap. Interestingly, informativeness has a significant effect on purchase intention 2 (high-involvement product). It is believed that cheap and smaller sized products sell better online. The earlier patterns have changed to the point that people buy mobile phones, personal computers and television sets online, as trust in online shopping grew.

People, however, seemed to collect information before they make a purchase decision regarding high-involvement products. The social network site, Weibo, is also a good place to find reviews and opinions. It may therefore be concluded that companies hoping to sell products on Weibo should focus on building enough or signification amounts of data and positive reviews of their products or services.

It is hoped that these findings contribute toward helping companies set a proper social commerce strategy by analyzing social network characteristics and their effect on purchase intention.

A limitation to consider is that this study was conducted based on a fictional simulation that Weibo offers online commerce service. It might be possible to derive different results when the social network site starts to provide an actual commerce service. Therefore, caution should be exercised when applying the findings to general social network commerce sites.

A future study could consider other variables such as gender, age to explain how they affect trust and purchase intention on social network commerce. Future research could also focus on non-retail products instead of retail products to see how social network characteristics affect decision makers' trust and purchase intention in their business.

\section{Acknowledgments}

This research is funded by NYIT Global Campus Faculty Summer 2013 Research Grants Program. The author is thankful for the survey assistance of NYIT School of Management students He Yanting and Zhang Jingqing.

\section{References}

An, D., \& Kim, S. (2008). A path analysis of consumer responses to the corporate website of Korean Air. Communication Science, 8(3), 314-346.

Borgatti, S., \& Cross, R. (2003). A relational view of information seeking and learning in social networks. Management Science, 49(4), 432-445. http://dx.doi.org/10.1287/mnsc.49.4.432.14428

Brackett, L. K., \& Carr, B. N. (2001). Cyberspace advertising vs. other media: consumer vs. mature student Attitudes. Journal of Advertising Research, 41(5), 23-32.

Chen, K., \& Yen, D. (2004). Improving the quality of online presence through interactivity. Information \& Management, 42(1), 217-226. http://dx.doi.org/10.1016/j.im.2004.01.005

Curty, R., \& Zhang, P. (2011). Social commerce: Looking back and forward. Proceedings of the American 
Society for Information Science and Technology, 48(1), 1-10. http://dx.doi.org/10.1002/meet.2011.14504801096

Davis, F. D. (1989). Perceived usefulness, perceived ease of use, and user acceptance of information technology. MIS Quarterly, 13(3), 319-340. http://dx.doi.org/10.2307/249008

Ducoffe, R. H. (1996). Advertising value and advertising on the web. Journal of Advertising Research, 36(5), 21-35.

Gafen, D., \& Straub, D. W. (2000). The Relative importance of perceived ease of use in IS adoption: A study of E-Commerce adoption. Journal of the Association for Information Systems, 1(8). 1-30. Retrieved from http://www.cis.gsu.edu/dstraub/Courses/MGS\%209940/2007/Tim-Mathieu-Betrice\%20choice.pdf

Gafen, D., Karahanna, E., \& Straub, D. W. (2003). Trust and TAM in online shopping: An integrated model. MIS Quarterly, 27(1), 51-90. http://dx.doi.org/10.2307/30036519

Jin, G., \& Lee, J. (2012). Service quality factors affecting satisfaction and repurchase intention of social commerce. Journal of Korea Contents Association, 12(3), 311-331.

Jones, Q., \& Rafaeli, S. (1999). User population and user contributions to virtual publics: A systems model. $A C M$ SIGGROUP conference on supporting group work. Retrieved from http://pdf.aminer.org/000/237/086/user_population_and_user_contributions_to_virtual_publics_a_systems.p df

Kim, S., \& Lim, Y. (2011). Consumers' perceived importance of and satisfaction with internet shopping. Electronic Markets, 11(3), 148-154. http://dx.doi.org/10.1080/101967801681007988

Lee, D., Lee, E., \& Kim, B. (2011). A study of influencing factors in internet shopping of the consumer's purchase intention. Journal of Management Information System, 30(1), 211-226.

Lee, J. (2011). A study on the communities loyalty and purchase intention in online shopping mall. Journal of E-Business, 12(3), 151-171.

Lee, J. (2012). A study on the structural relationship of interaction, identification, and loyalty of online brand community in China. Digital Policy and Management, 10(11), 235-241.

Li, H., \& Suomi, R. (2009). A proposed scale for measuring E-service quality. International Journal of u- and e-Service, Science and Technology, 2(1), 1-10. Retrieved from http://www.scribd.com/doc/53396037/A-Proposed-Scale-for-Measuring-E-service-Quality

Muniz Jr., A., \& O’Guinn, T. (2001). Brand community. Journal of Consumer Research, $27(4), 412-432$. http://dx.doi.org/ 10.1086/319618

Novak, T. P., Hoffman, D., \& Yung, Y. (2000). Measuring the customer experience in online environments: A structural modeling approach. Marketing Science, $19(1), \quad 22-42$. http://dx.doi.org/10.1287/mksc.19.1.22.15184

Rad, A. A., \& Benyoucef, M. (2011). A model for understanding social commerce. Journal of Information Systems Applied Research, 4(2), 63-73. Retrieved from http://proc.conisar.org/2010/pdf/1511.pdf

Rafaeli, S., \& Sudweeks, F. (1997). Networked interactivity. Journal of Computer-Mediated Communication, 2(4). Retrieved from http://onlinelibrary.wiley.com/doi/10.1111/j.1083-6101.1997.tb00201.x/full

Sedig, K., Parsons, P., \& Babanski, A. (2012). Towards a characterization of interactivity in visual analytics. Journal of Multimedia Processing and Technologies Special Issue on Theory and Application of Visual Analytics, 3(1), 12-28.

Stephen, A., \& Toubia, O. (2010). Deriving value from social commerce networks. Journal of Marketing Research, 47, 215-228. http://dx.doi.org/10.1509/jmkr.47.2.215

Wu, J., \& Chang, Y. (2005). Towards understanding members' interactivity, trust, and flow in online travel community. Industrial Management \& Data Systems, 105(7), 937-954.

Yoo, B., \& Donthu, N. (2001). Developing a scale to measure the perceived quality of an Internet shopping site, Quarterly Journal of Electronic Commerce, 2(1), 31-47. Retrieved from http://ebiz.bm.nsysu.edu.tw/2013/yen/Refference/Developing\%20a $\% 20$ scale $\% 20$ to $\% 20$ measure $\% 20$ the $\% 2$ 0perceived $\% 20$ quality $\% 20$ of\%20internet.pdf

Yun, H., Ahn, S., \& Lee, C. (2012). Determinants of Trust in power blogs and their effect on purchase intention. Journal of Korea Contents Association, 12(2), 411-418. 


\section{Copyrights}

Copyright for this article is retained by the author(s), with first publication rights granted to the journal.

This is an open-access article distributed under the terms and conditions of the Creative Commons Attribution license (http://creativecommons.org/licenses/by/3.0/). 